\title{
Rapid-onset Primary Biliary Cirrhosis Resembling Drug-induced Liver Injury
}

\author{
Tetsuro SoHda, Hiroshi ShIgA, Hidetoshi NaKane, Shinya NiShIZAwa, \\ Makoto YoshiKane, Akira AnAn, Norihisa SuzuKI, Makoto IRIE, \\ Kaoru IwATA, Hiroshi WatANABE and Shotaro SAKISAKA
}

\begin{abstract}
A 54-year-old woman was admitted to our hospital because of acute liver injury. Since she had a history of having used a diet product, drug-induced liver injury (DILI) was initially considered. However, the patient was subsequently diagnosed as suffering from primary biliary cirrhosis (PBC) based on the findings of liver histology and serum anti-mitochondrial antibody positivity. Overlap syndrome between PBC and autoimmune hepatitis (AIH) was also suspected, however, serum levels of aspartate aminotransferase, alanine aminotransferase and alkaline phosphatase became normal three months later, after treatment with combination therapy comprising ursodeoxycholic acid plus bezafibrate. We therefore concluded that the liver disease in this patient was actually PBC, but that it resembled overlap syndrome or DILI. In cases of PBC, a rapid onset, as frequently seen in the case of DILI, viral hepatitis or AIH, is not common. We herein report a rare case of $\mathrm{PBC}$ which resembled DILI. (Internal Medicine 44: 1051-1054, 2005)
\end{abstract}

Key words: primary biliary liver cirrhosis (PBC), overlap syndrome, rapid onset, diet product, druginduced liver injury

\section{Introduction}

Primary biliary cirrhosis (PBC) is known to be an autoimmune liver disease that occurs predominantly in middle-aged females. Most of the patients with PBC have no symptoms and the disease usually develops slowly without an acute onset or acute exacerbation $(1,2)$. Elevated serum levels of biliary enzymes, and histological findings, referred to as chronic non-suppurative destructive cholangitis (CNSDC), are the distinctive features of PBC (3). Furthermore, more than $90 \%$ of the patients show positivity for antimitochondrial antibody (AMA) in the serum, thereby greatly facilitating a diagnosis of PBC. Accordingly, the diagnosis of PBC is usually not so difficult in typical cases. However, we herein present a rare case of $\mathrm{PBC}$ which had been initially thought to be drug-induced liver injury (DILI), based on the fact that the patient had recently used a diet product, and the onset of the liver disease had been rapid.

For editorial comment, see p 1023.

\section{Case Report}

A 54-year-old Japanese woman had regularly received an annual medical check-up, including blood biochemistry, and liver disease had never been indicated. In May 2002, she began taking a diet product, and continued to take it for one week. The ingredients of this product comprised raspberry ketone (fruit), gymnema sylvestre (leaves), inositol, histidine, Job's tears (seeds), hyaluronate and vitamin C. Three weeks later, elevated serum levels of transaminase were noted at a medical check-up and she was referred to our hospital on July 3, 2002. She had no history of blood transfusion or alcohol abuse.

The laboratory data on admission are presented in Table 1. The levels of both transaminase and biliary enzymes were markedly elevated. Virus markers associated with hepatitis A virus, hepatitis B virus, hepatitis C virus, Epstein-Barr virus, cytomegalovirus, and herpes simplex virus were all negative (Table 2). Anti-nuclear antibody (ANA), AMA and antibody against M2 fraction of mitochondrial antigen (M2Ab) were all positive. The levels of immunoglobulin were within the normal range, with the exception of IgM, the level of which

From the Third Department of Medicine, Fukuoka University School of Medicine, Fukuoka

Received for publication January 11, 2005; Accepted for publication May 25, 2005

Reprint requests should be addressed to Dr. Tetsuro Sohda, the Third Department of Medicine, Fukuoka University School of Medicine, 7-45-1 Nanakuma, Jonan-ku, Fukuoka 814-0180 
Table 1. Hematological and Blood Chemistry Values on Admission

\begin{tabular}{|c|c|c|}
\hline \multicolumn{3}{|c|}{ Peripheral blood } \\
\hline WBC & $4,600 / \mu 1$ & (normal 3,900-9,300) \\
\hline $\mathrm{RBC}$ & $424 \times 10^{4} / \mu 1$ & (normal 425-571) \\
\hline $\mathrm{Hb}$ & $12.7 \mathrm{~g} / \mathrm{dl}$ & (normal 13.4-17.6) \\
\hline $\mathrm{Ht}$ & $40.3 \%$ & (normal 39.6-52.0) \\
\hline Plt & $16 \times 10^{4} / \mu 1$ & (normal 12.7-35.6) \\
\hline \multicolumn{3}{|c|}{ Blood chemistry } \\
\hline $\mathrm{TP}$ & $6.7 \mathrm{~g} / \mathrm{dl}$ & (normal 6.7-8.3) \\
\hline Alb & $3.7 \mathrm{~g} / \mathrm{dl}$ & (normal 4.0-5.0) \\
\hline$\gamma$-globulin & $14.8 \%$ & (normal 10.0-20.0) \\
\hline T-Bil & $0.6 \mathrm{mg} / \mathrm{dl}$ & (normal 0.3-1.2) \\
\hline D-Bil & $0.1 \mathrm{mg} / \mathrm{dl}$ & (normal $0.5>$ ) \\
\hline AST & $501 \mathrm{IU} / l$ & (normal 33>) \\
\hline ALT & $835 \mathrm{IU} / l$ & (normal 35>) \\
\hline $\mathrm{LDH}$ & $802 \mathrm{IU} / \mathrm{l}$ & (normal 260-485) \\
\hline ALP & $876 \mathrm{IU} / l$ & (normal 115-360) \\
\hline$\gamma$-GTP & $389 \mathrm{IU} / l$ & (normal 47>) \\
\hline ZTT & $12.3 \mathrm{~K} \cdot \mathrm{U}$ & (normal 4-12) \\
\hline $\mathrm{TC}$ & $155 \mathrm{mg} / \mathrm{dl}$ & (normal 130-220) \\
\hline TG & 194 mg/dl & (normal 35-150) \\
\hline
\end{tabular}

was increased to $307 \mathrm{mg} / \mathrm{dl}$ (Table 2).

Since the patient had a history of using a diet product, DILI was initially considered, although the findings of druginduced lymphocyte-stimulation test (DLST) with the diet product were in fact negative. However, serum biochemistry findings and positive AMA findings suggested $\mathrm{PBC}$. To clearly differentiate between PBC and DILI, a liver biopsy was performed.

Liver histology demonstrated infiltrating inflammatory cells, including a number of plasma cells, in the portal area, and destruction of the interlobular bile ducts, findings which are compatible with CNSDC (Fig. 1). Rosette formation was not discerned. Histopathological diagnosis was PBC stage II based on Scheuer's classification.

Administration of $600 \mathrm{mg} /$ day of ursodeoxycholic acid (UDCA) was initiated. Since a significant effect was not seen following monotherapy with UDCA, $400 \mathrm{mg} /$ day of bezafibrate $(\mathrm{BF})$ were added later. Three months after the initiation of this combination therapy, liver function was significantly improved and serum levels of aspartate aminotransferase (AST), alanine aminotransferase (ALT) and alkaline phosphatase (ALP) had become normal. The clinical course is shown in Fig. 2.

\section{Discussion}

We report a rare case of rapid-onset PBC. Most PBC cases are asymptomatic in the early stage and the disease progresses slowly. A rapid onset which is often seen in cases of viral hepatitis, autoimmune hepatitis (AIH), and DILI, is extremely rare in cases of PBC. For this reason, a health check-up is useful for pinpointing patients with asympto-
Table 2. Serological Data on Admission

\begin{tabular}{lr}
\hline Virus markers & \\
IgM HA antibody & $(-)$ \\
HBs antigen & $(-)$ \\
IgM HBc antibody & $(-)$ \\
anti-HCV antibody & $(-)$ \\
HCV RNA by RT PCR & $(-)$ \\
EBV IgM & $10>$ \\
EBNA & 40 \\
CMV IgM antibody & 0.29 \\
HSV IgM antibody & 0.84 \\
Immunology & \\
IgG & $1,360 \mathrm{mg} / \mathrm{dl}$ \\
IgA & $245 \mathrm{mg} / \mathrm{dl}$ \\
IgM & $307 \mathrm{mg} / \mathrm{dl}$ \\
IgE & $20>\mathrm{IU} / \mathrm{ml}$ \\
ANA & $1: 640$ \\
AMA & $1: 160$ \\
AMA-M2 & $79 \mathrm{U}$ \\
LKM-1 & $33 \mathrm{U}$ \\
ASMA & $(-)$ \\
\hline
\end{tabular}

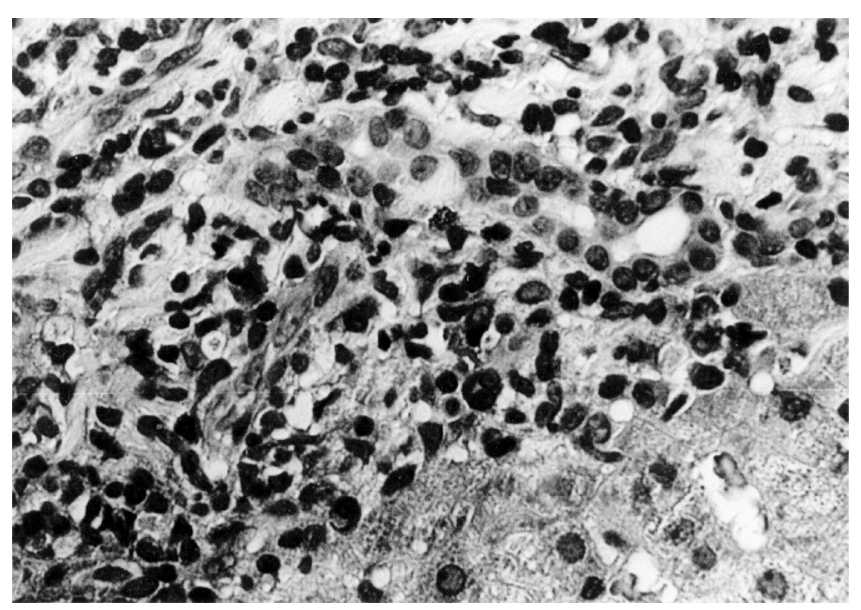

Figure 1. Liver histology demonstrates infiltrating inflammatory cells including a number of plasma cells in the portal area and destruction of the interlobular bile duct, findings which are compatible with CNSDC. However, rosette formation is not evident. These findings are characteristic of primary biliary cirrhosis (HE stain, $\times 40)$.

matic PBC. However, in the present case, liver disease had never been indicated during the patient's previous health check-ups, including serum biochemical examinations, thereby suggesting that the liver injury arising from PBC had developed rapidly.

Atypical cases of PBC are often difficult to distinguish from atypical AIH. Borderline disease between $\mathrm{PBC}$ and $\mathrm{AIH}$, known as overlap syndrome or PBC mixed type is still controversial (4-6). It is known that the serum levels of 


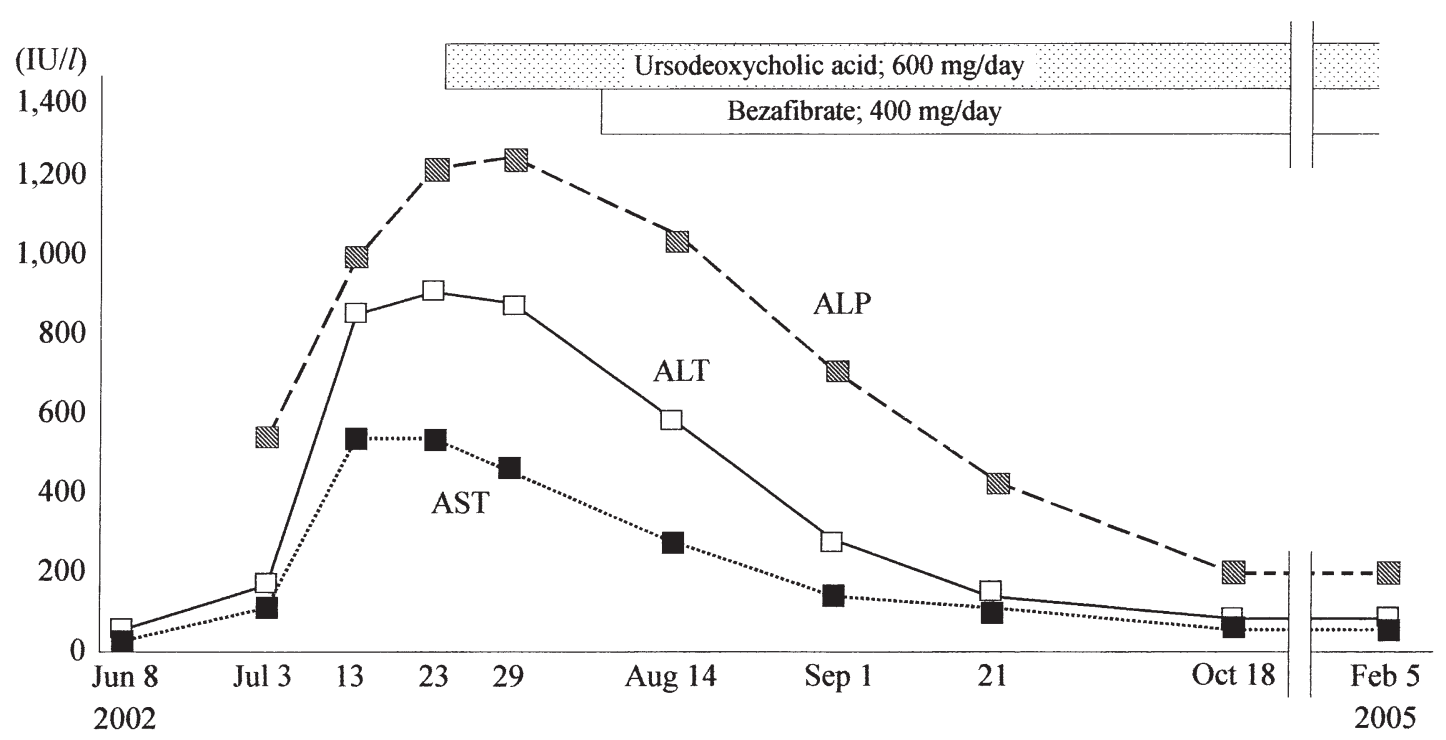

Figure 2. The clinical course is shown. Rapid-onset liver disease, which occurred three weeks after use of a diet product, was significantly improved and serum levels of AST, ALT and ALP became normal three months after combination therapy comprising ursodeoxycholic acid plus bezafibrate.

transaminase and $\gamma$-globulin seen in overlap syndrome are higher than those seen in pure PBC. Furthermore the HLA type has been reported to be different between the two diseases (7) however, there is as yet no conclusive evidence that this is truly so. Since, the publications of reports dealing with cases of AIH associated with bile duct injury, where the findings resembled those of CNSDC (8), it has become increasingly difficult to distinguish between atypical AIH and atypical PBC, even if histological analysis is performed. Although investigators have studied borderline disease using several different methods, including analysis of AMA by Western blotting (9-11), it is still difficult to distinguish pure $\mathrm{PBC}$ from overlap syndrome.

Overlap syndrome has the characteristics of both PBC and $\mathrm{AIH}$, and sometimes occurs acutely. The disease is also reported to have certain characteristics regarding the reaction to treatment. Several investigators reported that the liver function test is not completely normalized without corticosteroid treatment in most cases of overlap syndrome $(7,12)$, a fact that seems to be important.

UDCA is a unique drug approved for the treatment of PBC. Its multifarious pharmacological effects such as bile excretion-accelerating effect and liver cell-protecting effect are well known $(13,14)$. Recently, the anti-apoptotic effect of UDCA has also been elucidated $(15,16)$. On the other hand, the existence of $\mathrm{PBC}$ cases which are resistant to UDCA has also been pointed out. BF, a remedy for hyperlipidemia is known to reduce the serum levels of biliary enzyme (17). Recently, its efficacy against PBC was reported, and since then many follow-up studies have been performed. Moreover, its efficacy in cases of PBC which are not responsive to UDCA has also been reported. Thus, BF is attracting renewed attention as a remedy for $\operatorname{PBC}(18,19)$.

In the present case, the serum $\gamma$-globulin level was not increased, AMA was positive and ASMA was negative. Moreover, liver histology showed CNSDC, which is a characteristic feature of PBC. These findings are the typical findings of PBC, the exception being that the onset in this case was acute. Furthermore, it is highly important that in the present case, serum transaminase and biliary enzymes became normal about 3 months after the initiation of treatment which utilized both UDCA and BF. Since then, the liver function has remained normal for 30 months. For these findings, we thought that the liver disease of this patient was closer to PBC than overlap syndrome.

Recently, many cases of acute liver injury including fulminant hepatitis, following the ingestion of diet products have been reported in Japan (20). These diet products are mostly Chinese-made unapproved pharmaceuticals. Such DILI develops as acute liver injury with jaundice, and in several patients the result has been death due to liver failure. Cases of DILI, especially following consumption of a diet product have been increasing and this has now become an important problem in Japan.

In the present case, DILI was initially considered, because the patient had recently used a diet product. With regard to the diagnosis of DILI, a scoring system was advocated at the 6th Annual Meeting of the Japan Society of Hepatology (21). Based on this system, the present case would have fallen within the category of "possible", if a diagnosis of PBC had not been made. Accordingly, some effect from the ingested product can not be completely ruled out. Careful observations including histological follow-up are needed in this case of unusual rapid-onset PBC. 


\section{SOHDA et al}

Acknowledgements: The English used in this manuscript was revised by Miss K. Miller (Royal English Language Centre, Fukuoka, Japan).

\section{References}

1) Kaplan MM. Primary biliary cirrhosis. N Engl J Med 335: 1570-1580, 1996.

2) Neuberger J. Primary biliary cirrhosis. Lancet 350: 875-879, 1997.

3) Nakanuma Y, Ohta G. Histometric and serial section observations of the intrahepatic bile ducts in primary biliary cirrhosis. Gastroenterology 76: 1326-1332, 1979.

4) Popper H, Schaffner F. Non-suppurative destructive chronic cholangitis and chronic hepatitis. Progress in Liver Diseases, Vol III, Popper H, Schaffner F, Eds. Grune \& Stratton, New York, 1970: 336-353.

5) Klöppel G, Seifert G, Lindner H, Dammermann R, Sack HJ, Berg PA. Histopathological features in mixed types of chronic aggressive hepatitis and primary biliary cirrhosis. Correlation of liver histology with mitochondrial antibodies of different specificity. Virchows Arch A Pathol Anat Histol 373: 143-160, 1977.

6) Michieletti P, Wanless, IR, Katz A, et al. Antimitochondrial antibody negative primary biliary cirrhosis: A distinct syndrome of autoimmune cholangitis. Gut 35: 260-265, 1994.

7) Lohse AW, zum Büschenfelde KH, Franz B, Kanzler S, Gerken G, Dienes HP. Characterization of the overlap syndrome of primary biliary cirrhosis (PBC) and autoimmune hepatitis: Evidence for it being a hepatitic form of $\mathrm{PBC}$ in genetically susceptible individuals. Hepatology 29: 1078-1084, 1999.

8) Sato Y, Harada K, Sudo Y, et al. Autoimmune hepatitis associated with bile duct injury resembling chronic non-suppurative destructive cholangitis. Pathol Int 52: 478-482, 2002.

9) Surh CD, Roche TE, Danner DJ, et al. Antimitochondrial autoantibodies in primary biliary cirrhosis recognizes cross-reactive epitope(s) on protein $\mathrm{X}$ and dihydrolipoamide acetyltransferase of pyruvate dehydrogenase complex. Hepatology 10: 127-133, 1989.

10) Gershwin ME, Mackay IR. Primary biliary cirrhosis: paradigm or para- dox for autoimmunity. Gastroenterology 100: 822-833, 1991.

11) Nakanuma $Y$, Harada $K$, Kaji $K$, et al. Clinicopathological study of primary biliary cirrhosis negative for antimitochondrial antibodies. Liver 17: 281-287, 1997.

12) Chazouilleres O, Wendrum D, Serfaty L, Montembault S, Rosmorduc O, Poupon R. Primary biliary cirrhosis-autoimmune hepatitis overlap syndrome: clinical features and response to therapy. Hepatology 28 : 296-301, 1998.

13) Sakisaka S, Koga H, Sasatomo K, et al. Ursodeoxycholic acid reduces expression of heat shock proteins in primary biliary cirrhosis. Liver 20: 78-87, 2000.

14) Sakisaka S, Kawaguchi T, Taniguchi E, et al. Alternations in tight junctions differ between primary biliary cirrhosis and primary sclerosing cholangitis. Hepatology 33: 1460-1468, 2001.

15) Koga H, Sakisaka S, Ohishi M, Sata M, Tanikawa K. Nuclear DNA fragmentation and expression of Bcl-2 in primary biliary cirrhosis. Hepatology 25: 1077-1084, 1997.

16) Fiorucci S, Mencarelli A, Palazzetti B, Del Soldato P, Morelli A, Ignarro LJ. An NO derivative of ursodeoxycholic acid protects against Fas-mediated liver injury by inhibiting caspase activity. Proc Natl Acad Sci USA 98: 2652-2657, 2001

17) Day AP, Feher MD, Chopra R, Mayne PD. The effect of bezafibrate treatment on serum alkaline phosphatase isoenzyme activities. Metabolism 42: 839-842, 1993.

18) Kurihara $T$, Niimi A, Maeda A, Shigemoto M, Yamashita K. Bezafibrate in the treatment of primary biliary cirrhosis: comparison with ursodeoxycholic acid. Am J Gastroenterol 95: 2990-2992, 2000.

19) Ohmoto K, Mitsui Y, Yamamoto S. Effect of bezafibrate in primary biliary cirrhosis: a pilot study. Liver 21: 223-224, 2001

20) Kanda T, Yokosuka O, Okuda O, Suzuki Y, Saisho H. Severe hepatotoxicity associated with Chinese diet product 'Onshidou-GenbiKounou'. J Gastroenterol Hepatol 13: 354-355, 2003.

21) Takikawa H, Takamori $Y$, Hisamochi $A$, et al. A proposal of a new diagnostic criteria for drug induced liver injury-according to the modification of the diagnostic scale of the International Consensus Meeting. Acta Hepatol Jpn 44: 176-179, 2003 (in Japanese). 